\title{
Belgeo
}

Revue belge de géographie

$4 \mid 2005$

Miscellaneous

\section{Rosière S., Géographie politique et géopolitique. Une grammaire de l'espace politique}

Paris, Ellipses, 2003, 320 p.

\section{Christian Vandermotten}

\section{OpenEdition}

\section{Journals}

Édition électronique

URL : http://journals.openedition.org/belgeo/12221

DOI : 10.4000/belgeo.12221

ISSN : 2294-9135

Éditeur:

National Committee of Geography of Belgium, Société Royale Belge de Géographie

Édition imprimée

Date de publication : 31 décembre 2005

Pagination : 519-520

ISSN : 1377-2368

\section{Référence électronique}

Christian Vandermotten, «Rosière S., Géographie politique et géopolitique. Une grammaire de l'espace politique », Belgeo [En ligne], 4 | 2005, mis en ligne le 29 octobre 2013, consulté le 22 septembre 2020 URL : http://journals.openedition.org/belgeo/12221 ; DOI : https://doi.org/10.4000/belgeo.12221

Ce document a été généré automatiquement le 22 septembre 2020

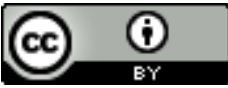

Belgeo est mis à disposition selon les termes de la licence Creative Commons Attribution 4.0 International. 


\title{
Rosière S., Géographie politique et géopolitique. Une grammaire de l'espace politique
}

Paris, Ellipses, 2003, 320 p.

\author{
Christian Vandermotten
}

\section{RÉFÉRENCE}

Rosière S., Géographie politique et géopolitique. Une grammaire de l'espace politique, Paris, Ellipses, $320 \mathrm{p}$.

1 Le sous-titre de l'ouvrage rend parfaitement sa nature. Il s'agit bien d'une grammaire raisonnée (et d'un vocabulaire) de la géographie politique et de la géopolitique, plutôt que d'un traité argumenté. Tel quel, l'ouvrage sera fort utile à qui cherche à la fois une information encyclopédique et son positionnement dans un cadre logique : il fournit des concepts opératoires pour des descriptions de géographie politique et la construction d'analyses géopolitiques. S'il ne videra sans doute pas la querelle sémantique sur l'usage des termes " géographie politique » et " géopolitique ", le choix fait par l'auteur a le mérite de la cohérence et sert de base à la structuration du livre : pour lui, la géographie politique décrit et interprète les espaces, qui sont les cadres de l'action politique, parmi lesquels il distingue les territoires (Etats, entités infra et supra-étatiques, ensembles socio-culturels), les lignes (frontières et réseaux) et les pôles (capitales, centres décisionnels, pôles spirituels et symboliques); la géopolitique examine pour sa part les rivalités de pouvoir dont les territoires sont les enjeux. Dans la seconde partie de l'ouvrage, qui lui est consacrée, l'auteur examine donc successivement les dynamiques des territoires, les acteurs qui y agissent et les types d'enjeux dont ils sont l'objet.

2 Un tel exercice implique nécessairement que certains concepts soient traités, sans doute faute d'espace, de manière assez réductrice. Il en est ainsi à notre sens de la 
notion de Nation ainsi que des partis, dont on voit mal pourquoi l'auteur les situe parmi les nouveaux acteurs et dont la typologie apparaît fort simpliste (et en outre ouesteuropéano-centrée). Quelques erreurs sont inévitables dans une telle entreprise, mais elles sont rares. Relevons-en deux. L'une à propos de Pankow présenté comme la capitale officielle de la RDA parce que Berlin-Est, capitale de fait, n'aurait pas eu le droit d'abriter la capitale du pays, alors que Pankow était un des Bezirke de Berlin-Est, qui abritait la résidence de plusieurs dirigeants du régime, le terme de "République de Pankow " étant utilisé pour marquer tout refus de légitimité à la RDA. L'autre est relative à la Région de Bruxelles-Capitale, dont la population n'est pas de 500000 habitants, mais de l'ordre du million et qui ne fait pas partie historiquement de la Flandre, mais bien du Brabant - la majorité de la population y parlait au XIX siècle un dialecte flamand-brabançon (les auteurs français ont décidément bien du mal à faire la différence entre les Flandres - les deux provinces homonymes - et la Flandre, ou plutôt la Région flamande). Ceci est de peu d'importance et ne doit pas masquer l'intérêt de l'ouvrage pour qui veut aborder avec rigueur une étude de géographie politique ou de géopolitique. 